ELORE (ISSN 1456-3010), vol. 17 - 2/2010.

Julkaisija: Suomen Kansantietouden Tutkijain Seura ry.

[http://www.elore.fi/arkisto/2_10/saarikoski_2_10.pdf]

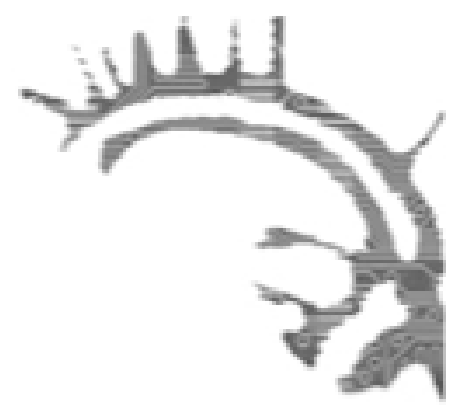

\title{
Kolumni
}

\section{TANSSI KIRJOITUKSENA, KIRJOITUS TANSSINA}

\section{Helena Saarikoski}

Kirjoitettu teksti on edelleen, kaikista kokeiluista huolimatta, jokseenkin ainoa hyväksytty tapa esittää tieteellisen tutkimuksen tulokset akateemiselle yleisölle. Kun tutkimuskohde on tanssi, ihmisliikkeen sanaton esitysjärjestys, kysymykset kirjoittamisen rajoista ja mahdollisuuksista käyvät askarruttamaan (ks. myös Saarikoski 2003, 11-16). Meneillään olevassa lavatansseja koskevassa tutkimuksessani kysymys on samalla lähdekritiikistä, koska tutkimuksen aineisto on tutkittavien ihmisten kirjoittamaa. Toivon aineiston kirjoituksilta vastauksia joihinkin tutkijankin tanssikirjoittamisen kysymyksiin.

\section{TANSSIKENTÄLLÄ ARKISTOSSA}

Olin pitkään tiennyt Museoviraston arkistossa olevasta Lavatanssit-keruusta, mutta koskaan ei ollut oikein aikaa tutustua aineistoon pinnallista silmäilyä enempää: yli kymmenentuhatta arkistoliuskaa Museoviraston vastaajaverkkoon kuuluvien kirjoittajien vastauksia kyselyyn, jonka Aila Nieminen oli tehnyt kerätäkseen aineistoa kansatieteen graduunsa (Nieminen 1991; Nieminen 1993). Olin nyt lähdössä tutkimaan kansanomaista tanssikulttuuria, muistiin kirjattuja kokemuksia ja elämyksiä, menneitä ruumiinkulttuureja.

Olin jo rakennellut mielessäni suuria suunnitelmia Museoviraston aineiston varaan siinä vaiheessa vuonna 2008, kun viimein sain raivattua aikaa ja ajoin raitiovaunulla vihreälle talolle Nervanderinkadun mutkassa, entiselle koululleni, jossa Museoviraston arkisto sijaitsi. Siellä istuin, nyt arkistosalissa, kuin 1970-luvun alussa koululuokassani, pöydälläni ensimmäinen Lavatanssit-kokoelman 21:stä arkistoliuskojen nipusta. Luin alusta alkaen kymmeniä liuskoja kasvavan hämmästyksen, pettymyksen ja turhautumisen vallassa: onko kaikki tämä valtava aineisto käyttökelvotonta nykyisen tanssintutkimuksen kysymysten, ihmisten kokemushistorian ja ruumiin- 
kulttuurin kysymysten, kannalta? Luin liuska toisensa perään yksisanaisia vastauksia keruulehden kysymyksiin, jotka vastaaja oli ilmaissut numeroilla marginaalissa. Luin ulkoisten faktatietojen luetteloita: minkälainen lava rakennettiin mihin, koska, miten lavan sitten kävi. Luin passiivin teoista ja tapahtumista, jotka olivat koskettaneet nollapersoonaa.

Kunnes yhtäkkiä pitkän, yli sataliuskaisen kirjoituksen alkupuolella kertoja muistelee iltamia, jotka on järjestetty hänen lapsuudessaan eteläpohjalaisen kotitalon tuvassa. Kertomus päättyy samaan kuin iltamat tapasivat tuohon aikaan päättyä, tansseihin:

\begin{abstract}
Lopuksi oli tanssia jota tanssivat Aati Tikkasen viulun soiton tahdissa. Sitten isää haki eräs nuori leski emäntä Syrjälän Senija tanssimaan ja se oli polkkaa. He olivat kuulemma molemmat erittäin hyviä tanssimaan, kuulin aikuisten jälkeenpäinkin kertovan. - Tanssimaan hakeminen ensiksi ei siihen aikaan kuulunut naisille, pojat hakivat ensin ja vasta "takaisinhaku" kuului tyttöille eli naisille. Mutta isä ja tuo Senija olivat perhetuttavia että Senija oli isän sisaren Miinan, miehen sisko. Isä seisoi meidän lasten kanssa kammarin ovella katsomassa tanssivia niin se Senija tuli isän luo ja sanoi vain yksinkertaisesti ja hymyilevänä jotta "tuuppas Kalle tanssimaan". Ja niin he lähtivät menemään mielestämme aika vinhaa vauhtia mutta ei se mitään rytkypolokkaa eikä hevospolokkaa ollut. Isä nosti aina jossain kohdassa toista jalkaansa polvikoukusta suorassa kulmassa taakseppäin niinkun olisi mennyt toisella jalalla. Se Senija oli hyvin sievä ihminen niinkun sanottiin: hoikka, ja paksu musta tukka nutturalla ja suuret mustat silmät joita hän nauraen väläytteli. (MVK37:726).
\end{abstract}

Tähän lukemiseni katkesi viikoiksi. Näkymä isä-Kallesta ja nuoresta Senijasta vinhassa polkassa ei jättänyt minua rauhaan. Kertomuksen muisto seurasi mukanani arjen kiireissä; aistin tanssien juhlatunnelman, musiikin ja liikkeen riehakkaan ilon, ihailun, jota kertojan on täytynyt tuntea katsellessaan pienenä tyttönä kammarin ovelta isänsä ja tuttavanaisen tanssia. Tajusin, että jos aineiston viidelläkymmenellä liuskalla on yksi tällainen kertomus, koko aineistossa täytyy olla satoja vastaavia: kertomuksia, jotka herättävät menneet kokemukset eloon lukijalle tässä ja nyt, jotka liikuttavat läheisyydellään ja jotka kuvaavat kokemukset ymmärrettävinä tutkittavan kulttuurin yhteydessä. Kokemustensa kertojat eivät ainoastaan kerro menneistä tai menneitä koskevista muistoistaan; he liikkuvat kertomuksissaan menneisyyden tanssilattioilla. Heidän liikkumisensa kertomuksissaan liikuttaa jotain minussa, kertomuksen lukijassa (ks. Saarikoski tulossa 2011).

Luin Hanna Väätäisen yhteisötanssiryhmää koskevan etnografisen tutkimuksen (2009), myös nimenomaan tanssikirjoittamisen kannalta inspiroivan ja uusiin ajatuksiin vievän kirjan, tuoreeltaan syksyllä 2009. Sovellan ajatuksia tutkimuksen ja tanssin lomittumisesta, kun kuljen aamuisin arkistoon, seuraavana talvena ja keväänä.

Olkalaukkuni kannettavine tietokoneineen on järkyttävän paljon painavampi kuin laukkuni nelisenkymmentä vuotta sitten, koulumatkalla. Muistoni tällä tiellä alkavat niihin aikoihin, joihin lavatanssikirjoittajien muistelut päättyvät. Silloin, koulutiellä, samaa matkaa tuntui olevan edessä loputon aamujen luku, määränpäässä aina sama koulupäivä. Nyt jokainen päivä, jonka pystyn pistämään arkistoon, on arvokas, ko- 
neen tuskastuttavasta raahaamisesta huolimatta olen innokas, utelias. Avaan koneeni arkistosalin pöydälle, haen aineistonipun ja alan lukea. Kirjoittaja kerrallaan tulee lähelle tai jää etäämmälle kertomuksessaan. Kirjoitus liikuttaa silmiäni riveillään, sormiani koneeni näppäimistöllä, sähköisiä impulsseja koneessa - tullakseen liuska liuskalta käännetyksi luettujen pinoon ja niputetuksi takaisin arkistolaatikkoon. Vähän väliä nousen ylös ja käyn jossain, hakemassa uusia aineistonippuja, kahvilla, syömässä, olen levoton, tuijotan ikkunasta ulos niin kuin joskus lapsena, en tiedä missä olen enkä kuule mitään täältä. En seuraa enkä vie.

Arkistopäivien kertyessä tanssimuistojen lukeminen ja kirjoittaminen koneelle arkistosalin hiljaisuudessa, jossa työskentelen useimmiten yksin, synnyttää kummallisen, odottamattoman ristiriidan. Luen ja kirjoitan päivästä toiseen: yhdessä liikkuvista ihmisruumiista, soivasta musiikista, iloisista seurueista ja juhlan tunnelmista; kaikin puolin sen tilan vastakohdasta, jossa luen ja kirjoitan. Mitä enemmän luen, sitä enemmän kirjoitukset vievät mennessään, liikuttavat ja ihastuttavat, houkuttavat lukemaan yhä lisää, ja sitä hiljaisemmaksi ja liikkumattomammaksi tunnen itseni käyvän arkistopöydän ääressä. Tanssimuistelut saavat tilaa minussa, ne vievät kaiken tilan, tulen kotiin ja saan koneeni laukustaan työpöydälle, en ole enää vain levoton, on levottomat jalat, haluan musiikkia, tanssia, syödä, juoda, siivota, uida ja kylpeä, surffata netissä, kaikkea ja kaikkea paljon ja täysillä ja yhtä aikaa. Illat ovat yhtä ilotulitusta.

Miten suodattaa tätä sekoitusta, annostella ristiriidan ainesosia tutkimustekstiin sopivissa suhteissa niin, että aineiston kirjoittajien ruumiillinen läsnäolo kerrotuissa tilanteissa tulee esille ja pääsee oikeuksiinsa, mutta sitä tutkijasubjektiakaan ei nosteta näkymättömiin, jonka lukukokemuksissa kertojien läsnäolo on toteutunut?

\section{TUTKIMUS TANSSINA}

Kysymykseni lähtevät huomiosta, että tanssintutkijat tahtovat usein mallintaa joko koko tutkimuksensa tai tutkimuskirjoittamisensa tanssiksi. Esimerkeiksi käyvät Valerie Janesickin (2000) artikkeli, otsikoltaan suomennettuna "Laadullisen tutkimusasetelman koreografia: menuetteja, improvisaatioita, kiteytyminen" tai Susan Fosterin (1995) artikkeli "historian tanssikirjoittamisesta" tai "historian tanssillistamisesta”. Hanna Väätäinen (2009, 32 ym.) on kuvannut tanssista kirjoittamistaan konkreettisin ruumiillisin termein. Tutkijan sormien tanssi näppäimistöllä täyttää tanssin määritelmäkriteerit, samoin hänen mielessään tai aivoissaan tapahtuva käsitteiden abstrakti tanssi, liikkuva ja muuttuva mielteiden konstellaatio, joka on ruumiillinen osa tutkimusprosessia siinä missä kirjoittaminenkin.

Sinänsä ajatus tutkimuksen mallintamisesta tutkimuskohteen mukaan ei ole tanssintutkijoiden erikoisuus, vaan sen ovat esittäneet monen monet eri alojen kulttuurientutkijat - eikä ajatusta ole tarkoitettu vain vertauskuvaksi (ks. Saarikoski 2009, 14, 60). Hermeneuttisen epistemologian mukaan tutkija on väistämättä osa tutkimuskohdettaan. Loogista on, että tutkimuskohde ja itse tutkimus samaistuvat: 
tutkijalla ei ole lopulta pääsyä kuin omaan tutkimukseensa, omiin kuvauksiinsa kohteesta; hänen havaintonsa ovat hänen omista havainnoistaan; tämän tiedostamista - aina tutkimustekstiin asti - edellytetään pätevyystarkastelussa.

Yksi kysymyksistäni on, olisiko tästä tutkimuksen normiksi tai ihanteeksi. Pitäisikö vaikka rockklubien etnografian jotenkin itse "rokata" tutkimuksena? Tutkimukselle asetettavana vaatimuksena tällainen voi tuntua oudolta ja synnyttää vastaväitteitä. Jatkan ajatuslinjaa: jos tutkimusta ei mallinneta tutkimuskohteen mukaan, minkä mukaan sitten? Jos tutkimuskohde ei muotoile tutkimusta, mikä sen muotoilee? Vastaus on arvattavasti vallitsevien akateemisten diskurssien paradigmaattiset standardit, jotka määrittelevät ja sanallistavat tutkimuskohteen ulkoapäin, ilman huomiota tai kiinnostusta tutkittavien ihmisten kokemuksiin ja näkemyksiin. Paikallinen tietämys ja tietämisen tavat alistetaan elitistisille akateemisille tietämisen tavoille. Voidaan uumoilla eräänlaista intellektuaalista tai epistemologista kolonialismia.

Vastaukseni ensimmäiseen kysymykseen näyttää siis olevan myönteinen: kyllä, tutkimuskohteen tulisi muotoilla ja mallintaa itse tutkimusta ja tutkimustekstiä. Seuraava kysymys on, miten ajatus toteutetaan. Olemme folkloristeina oppineet kiinnittämään huomiota metafolkloreen, itse perinteessä ilmaistuihin käsityksiin perinteestä. Lavatanssiaineiston kirjoittajatkin ovat kommentoineet kirjoittamistaan, esimerkiksi toistuva huomio: vastaaja kertoo ajatelleensa ensin, ettei tiedä tai muista tästä aiheesta mitään, mutta nyt kun hän on kirjoittanut tätä vastaustaan, monet muistot ovat alkaneet tulla mieleen ja seuranneet toistaan kirjoituksen edetessä. Kirjoituksen metakommentteja voin käyttää muotoillakseni tanssijoiden tapaisen tanssikirjoittamisen suuntaviivoja. Mutta etsittävänä tuntuu olevan jotain perustavampaa, jos päämääränä on lavatanssien tutkimus lavatanssina tai tanssinomainen tutkimus, kohteen mallinen tutkimus.

Sanoin jo, että aion katsoa kertojien liikkuvan kirjoituksissaan kerrotun menneisyyden tanssilattioilla. Toisin sanoen, aion katsoa heidän kertomuksiaan tanssina. Kirjoitusten tutkimista ei näin käsitteellistetä heikommaksi tavaksi tietää tanssista, verrattuna vaikkapa itse tanssimiseen, osallistuvaan havainnointiin tai havainnoivaan osallistumiseen (tanssin katsomisesta tutkimusmenetelmänä Väätäinen 2003, 131-147). Jos kerran tanssintutkijat voivat pitää omaa kirjoittamistaan tanssimisensa muotona, miksei tutkittavien ihmisten kirjoituksia tansseistaan pidettäisi heidän tansseinaan?

Aineiston kirjoittajat eivät luultavasti allekirjoittaisi, ainakaan siltä istumalta, ajatustani. Voi siis kysyä, edustaako tämä ajatus paikallisen tietämyksen horisontin tarpeellista laajennusta, vai ehkä pikemmin tutkittavien ihmisten omien kulttuuristen ymmärrysten vääristämistä (vrt. Saarikoski 2009, 127, viittaa Clifford Geertziin). Myönnän, että tiedon tasolla aineiston kirjoittajat eivät varmasti hyväksyisi väitettä, että kirjoittaminen on tanssimista; he eivät ole ajatelleet kirjoittamistaan tanssina. Mutta eloisien, intensiivisten muistojen hetkillä kuvittelen, että he ovat voineet tuntea kirjoittaessaan tanssivansa. He ovat kertomuksessaan tanssineet mielessään.

Näin laajan kirjoitetun, tanssikokemuksia yksityiskohtaisesti ja konkreettisesti kertovan aineiston olemassaolo osoittaa, että sanallistaminen ja kirjallinen kertominen on yksi tanssin esittämisen tapa, itse asiassa tanssimisen muoto, joka on myös kansanomainen, ei vain tanssintutkijoiden oman tanssimisen muoto. Tutkimuskirjoittaminen 
Helena Saarikoski: Tanssi kirjoituksena, kirjoitus tanssina

toisten kirjoittamasta aineistosta ei pyri jäljittelemään (siteeraamaan) eikä kertomaan (referoimaan) aineistoa vaan esittämään siitä uudelleentulkinnan tutkimuskirjallisuuden tyylilajissa. Etnografinen tanssikirjoittaminen ei siis merkitse tutkittavan tanssin mimeettistä jäljittelyä, matkimista, eikä tanssikulttuurin representaatiota, edustamista, aineiston kirjoittajien puolesta puhumista, vaan tutkimuskohteen esittämistä, presentaatiota, tutkimuksen esitysjärjestyksen kehyksissä (ks. Hastrup 1995, 21).

\section{ÄLKÄ̈̈ KOKEILKO KOTONA?}

Niin sanottu uusi kokeileva etnografia, keskustelu etnografian kirjoittamisesta, poetiikasta ja politiikasta, on vähintään parikymmentä vuotta vanhaa ja kuuluu jo etnografian valtavirtaan, ellei suorastaan kaanoniin (esim. Richardson 2000, joka viittaa erittäin laajasti lähdekirjallisuuteen). Suomalaiseen tutkimuskirjoittamiseen uutuus ei juuri ole kotiutunut - joitakin merkittäviä poikkeuksia on. Ajattelen lukemistani kirjoista Senni Timosen kalevalamittaisen kansanlyriikan tutkimusta (2004) ja Hanna Väätäisen yhteisötanssitutkimusta (2009). Näissä tutkimuskirjoissa kirjoittamisen tapa ja tyyli vievät lukijan osallistumaan tutkimukseen kirjoittajan kanssa. Kielen ja kerronnan laatu, niin erilaisia kuin ne kahdessa kirjassa ovatkin, tuntuvat osoittavan, että tutkimuskohteesta ei voi puhua muuten kuin kielellä, joka - jollain määrittelemättömällä tavalla - noudattelee tutkittavan omaa ominaislaatua. Kun tutkimuksessa edetään todella uuteen tietoon, vain uusi kieli voi venyttää totutun ajattelun rajoja.

Mietin, onko syynä suomalaisen tutkimuskirjoittamisen kaavamaisuuteen se, että suhteettoman suuri osuus tutkimuksen volyymista koostuu yliopiston opinnäytetöistä ja järjettömän monen viimeiseksi tutkimustyöksi jää korkein opinnäyte. Arvioijaportaaseen yleneminen yliopistollisella virkauralla suosii hapuilun ja uuden etsimisen sijasta ennen kaikkea tervettä herranpelkoa ja akateemisten muotokaavojen palvelusta. Opinnäytteen arviointimenettelyyn alistaminen ei totisesti innosta improvisointeihin, ennakoimattomiin luoviin liikkeisiin, eikä suo sijaa luodun vapaaseen, pelottomaan esittämiseen (etnografisesta improvisoinnista ks. Väätäinen 2009, 37-43; luovien analyysikäytäntöjen etnografiasta Richardson 2000). Opinnäytteen kirjoittaminen on pikemmin kuin huippu-urheilua, kilpatanssin tarkoin määriteltyihin kuvioihin pakotettua tiukkaa valmentautumista.

Yliopisto tuottaa tällä hetkellä aivan liikaa tutkintoja vähät välittäen niille hyväuskoisille ihmisille aiheuttamastaan vahingosta, joiden selkänahasta se ottaa nämä tulospisteensä. Valistunut vastaus koulutuspetoksen uhriksi joutumiselle tuskin on niellä purematta kaikki muukin systeemin syöttämä pajunköysi. Kilpailutilanne, johon nyt valmistuvat maisterit ja tohtorit joutuvat, ei ole ehkä aivan suoraan samaistettavissa pula-ajan maratontansseihin (McCoy 1935). Sellaisiin hätäpäissä ilmoittautumisen sijasta viisasta rohkeutta saattaisi olla opetella löytämään omat askeleensa ja ottamaan oma tila niiden esittämiseen tavoittelematta ensi sijassa markkina-arvoista palkintoa. 
Helena Saarikoski: Tanssi kirjoituksena, kirjoitus tanssina

\section{Aineisto}

Museovirasto (MV), kansatieteen keruuarkisto, K37 Lavatanssit (1991).

\section{KiRJALlisuUs}

FOSTER, SUSAN 1995: Choreographing history. - Foster, Susan (ed.): Choreographing History. Bloomington: Indiana University Press.

HASTRUP, KIRSTEN 1995: A Passage to Anthropology. Between experience and theory. London: Routledge.

JANESICK, VALERIE 2000: The Choreography of Qualitative Research Design: Minuets, Improvisations, and Crystallization. - Denzin, Norman K. \& Lincoln, Yvonna S. (eds.): Handbook of Qualitative Research. Second edition. Thousand Oaks: Sage.

MCCOY, HORACE 1935: They shoot horses, don't they? New York: Simon \& Schuster. Suom. Heikki Salojärvi 1978: Ammutaanhan hevosiakin. Helsinki: Love.

NIEMINEN, AILA 1991: Lavatanssit. - Museoviraston kyselylehti 1991. Helsinki: Museovirasto, kansatieteen toimisto.

NIEMINEN, AILA 1993: "Tanssilava, järvi ja hanuri". Lavatanssit Suomessa vuosisadan vaihteesta 1960-luvun loppuun asti. Julkaisematon etnologian pro gradu -tutkimus, Jyväskylän yliopisto.

RICHARDSON, LAUREL 2000: Writing: A Method of Inquiry. - Denzin, Norman K. \& Lincoln, Yvonna S. (eds.): Handbook of Qualitative Research. Second edition. Thousand Oaks: Sage.

SAARIKOSKI, HELENA 2003: Ruumiintekniikoista tanssien antropologiaan. - Saarikoski, Helena (toim.): Tanssi tanssi. Kulttuureja, tulkintoja. Helsinki: SKS.

SAARIKOSKI, HELENA 2009: Nuoren naisellisuuden koreografioita. Spice Girlsin fanit tyttöyden tekijöinä. Helsinki: SKS.

SAARIKOSKI, HELENA tulossa 2011: Menneisyyden ruumiinkokemusten tutkiminen kirjoitetuissa aineistoissa. - Tulossa teoksessa Lakomäki, Sami, Laurén, Kirsi \& Latvala, Pauliina (toim.): Teksteistä tutkimukseksi. Monitieteisiä näkökulmia kirjoitettuihin aineistoihin. Helsinki: SKS. Käsikirjoitus $17 \mathrm{~s}$.

TIMONEN, SENNI 2004: Minä, tila, tunne. Näkökulmia kalevalamittaiseen kansanlyriikkaan. Helsinki: SKS.

VÄÄTÄINEN, HANNA 2003: Rumbasta rampaan. Vammaisen naistanssijan ruumiillisuus pyörätuolikilpatanssissa. Åbo: Åbo Akademis förlag.

VÄÄTÄINEN, HANNA 2009: Liikkeessä pysymisen taika. Etnografisia kokeiluja yhteisötanssiryhmässä. Turku: Eetos.

Folkloristiikan ja naistutkimuksen dosentti, filosofian tohtori Helena Saarikoski on helsinkiläinen vapaa tutkija ja tietokirjailija, joka harrastaa seitsemättätoista vuotta itämaista tanssia. 